\title{
Critically Reflective Pedagogical Model: a Pragmatic Blueprint for Enhancing Learning and Teaching in Construction Disciplines
}

\author{
Imriyas Kamardeen \\ Faculty of Built Environment, University of New South Wales, Australia
}

\begin{abstract}
University lecturers who aspire to provide an improved learning experience for their students continually, and be recognised for high quality teaching should embrace a critically reflective practice. Nonetheless, developing as a reflective lecturer is challenging, although there are pedagogical literatures as general guidelines. This study introduces a new pedagogical model of critically reflective practice to simplify the efforts for lecturers and to shorten their journey to becoming effective teachers. A two-phased action research strategy was adopted for the development and validation of the new model. The first phase operationalised the Brookfield's four-lens framework to create a reflective teaching practice model, which was then validated with a case study in the second phase. The model offers a pragmatic blueprint for lecturers to build a career with sustained quality of teaching, which in turn translates into improved learning experiences for students.
\end{abstract}

Keywords: Higher education, pedagogy, critically reflective practice, teaching quality, learning experience.

Paper Type: Research article

\section{Introduction}

Scholarships of learning and teaching in higher education strongly advocate that critically reflective educators are excellent educators who continually improve the worthiness of their teaching by repeated refining of their pedagogical approach. McKay (2007), for instance, claimed that critically reflective educators possess many qualities that can deliver better learning experiences for students. These include the following: (1) Critically reflective educators lead a more innovative practice, freeing themselves from routine behaviours, and they often consider different methods of delivering a particular module to make learning more effective; (2) Critically reflective educators are self-driven in their professional development. They continually learn about effective pedagogical practices by attending seminars/workshops and through readings; and (3) Critically reflective educators are actively involved in the overall program/curriculum planning, development and change at the school level, that drive a more effective teaching.

Being critically reflective educators not only benefits students, but also the lecturers themselves. They are able to obtain better teaching evaluations from students, and recognitions within the faculty, for their active engagements with the overall learning and teaching portfolio. Moreover, they naturally contribute to the scholarship of learning and teaching through publications. Based on the author's observations, it was critically reflective educators who mostly receive teaching excellence awards at the faculty and university levels. Hence, embracing a critically reflective teaching practice is beneficial for both lecturers and students.

\footnotetext{
Copyright: Construction Economics and Building 2015. (C) 2015 Imriyas Kamardeen. This is an Open Access article distributed under the terms of the Creative Commons Attribution 4.0 Unported (CC BY 4.0) License (https://creativecommons.org/licenses/by/4.0/), allowing third parties to copy and redistribute the material in any medium or format and to remix, transform, and build upon the material for any purpose, even commercially, provided the original work is properly cited and states its license.
}

Citation: Kamardeen, I., 2015. Critically reflective pedagogical model: a pragmatic blueprint for enhancing learning and teaching in construction disciplines, Construction Economics and Building, 15(4), 63-75. DOI: http://dx.doi.org/10.5130/AJCEB.v15i4.4607

Corresponding author: Imriyas Kamardeen; Email - imriyas@unsw.edu.au

Publisher: University of Technology Sydney (UTS) ePress 
Reflective teaching practice, as a paradigm, is applied across different levels; pre-schools, schools, teacher education colleges and universities. The pathway that one should take to become a critically reflective educator is significantly influenced by the teaching and learning context. In universities, disciplinary variation may have an impact too. Moreover, the pathway can be long and demands significant efforts from lecturers, which may eventually discourage them.

To this end, the aim of this study has two folds: (1) demonstrating how one can adopt a critically reflective practice in construction management discipline; and (2) offer a pragmatic, off-the-shelf model that lecturers can adopt to lead a critically reflective career, and thereby improve teaching quality. In addressing the aim, the paper first explains the pedagogical theory that underpins this study. Then the research methodology is outlined. Following that the implementation of the research methodology to achieve the aims are expounded. Finally, conclusions are drawn.

\section{Theoretical Background}

Le Cornu and Peters (2005) defined reflective educator as one who engages himself/herself in critically reflective processes whilst Schon (1990) defined the reflective practitioner as one who is engaged in "reflection-in-action". Critical reflection in practice or reflection-in-action is elaborated by Rolfe, Freshwater and Jasper (2001) as deliberating methodically and meticulously over one's practice to learn from actions, thereby making impactful changes to it. Johns (2002) concurred that a process of self-enquiry grounded on guided reflections allows a practitioner to realise effective strategies for the practice.

Developing as a reflective lecturer is a learnt behaviour that requires time and practice. Equally, a strategic pathway should be followed for the process so that the best outcomes can be reaped. In a seminal work, Brookfield (1995) proposed a four-lens framework that can be engaged to become a critically reflective lecturer. The lenses proposed by Brookfield are as follows:

1. The autobiography (self-reflection) - is the footing of critical reflection in that lecturers focus on their experiences as learners. This enables the lecturers to see their practice from the point of view of "what their students experience".

2. The students' eye (student feedback) - relates pedagogical approaches that may need adjustments or that can be improved for better effects.

3. The colleagues' eye (peer assessment) - fostering critical conversations with colleagues, through mentoring, advice seeking and feedback, about one's teaching can yield useful insights for practice.

4. Theoretical literature (engaging with scholarly literatures) - lecturers who research, present and/or publish scholarly work about their teaching demonstrate an enlarged, forwardthinking practice.

This framework has been well-received and largely adopted in universities as an overarching guide that can be utilised by desiring lecturers to lead a reflective practice.

\section{Research Method}

Figure 1 illustrates the research methods adopted for this study, which had two distinct phases. In the first phase, the Brookfield's four-lens framework was operationalised for developing a new reflective teaching practice model. Qualitative data from four different sources such as selfreflections, students' views, colleagues' views and literature review were collected and subjected to a comprehensive thematic analysis, which resulted in a new pedagogical model. The second phase tested and validated the model with a case study. The case was a module taught by the author. The pedagogical strategies postulated by the model were absorbed in the design and 
delivery of the module. At the end of the teaching period, a questionnaire survey was conducted amongst students who took the module, to evaluate the quality of learning and teaching, which indirectly measured the effectiveness of the proposed pedagogical model. Descriptive statistics were computed for the survey data collected. The ensuing sections describe these research processes and outcomes in detail.

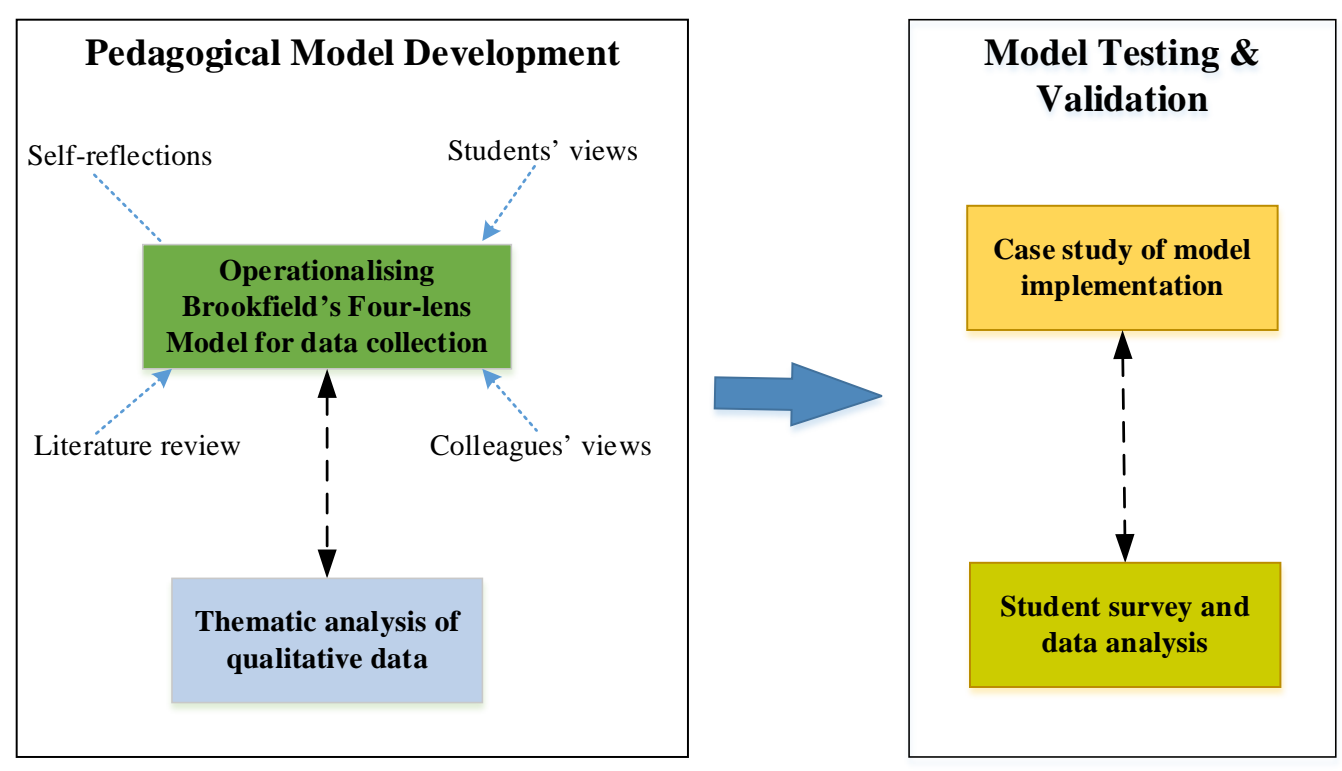

Figure 1: Research method

\section{Developing a Model for Critically Reflective Teaching Practice}

This phase of the research essentially involved the operationalisation of the Brookfield's fourlens framework in the author's work settings for critical reflection and then for creating a new pedagogical model. Data collection and analysis at this phase were purely qualitative. Data collected from four different sources were subjected to a thematic content analysis. The findings were then consolidated to inform the development of a new, reflective teaching practice model. The subsequent sections elaborate on different examinations performed with the four lenses and the model formulation.

\section{Examining with lens 1: the autobiography as a construction leaner}

As the starting point of critical reflection, the author contemplated over the teaching received during his undergraduate and postgraduate studies. Four themes were adopted to neatly organise the reflections, including: (1) characteristics of the lecturer; (2) module delivery methods; (3) learning resources provided; and (4) assessment methods. Table 1 depicts the reflections under two columns, known as "Qualities I liked" and "Qualities I disliked".

\section{Examining with lens 2: students' views on the effectiveness of learning and teaching}

Students are the direct consumers of teaching as they experience its effects on their learning firsthand. Because students experience a profound impact of teaching, their judgement on the effectiveness of teaching should be given significant considerations. Moreover, the main source for student feedback is their rating of teachers and teaching. Hence, the second part of the reflection involved interrogating past student feedback on the author's modules.

The author collected student feedback received for three modules he taught over two consecutive years. The feedback is referred to as CATEI, which has two forms: Form A 
(Evaluate the Module) and Form B (Evaluate the Module Lecturer). There were responses from 99 students (out of 155) from the three modules in both forms. A detailed content analysis of CATEI results was undertaken, in that attention was paid to the qualitative feedback provided by students on both forms. Subsequently, students' comments were aggregated, as outlined below, under the same four themes.

\section{Student preferred lecturer characteristics}

The students identified several important traits of effective lecturers, viz.: (1) having up-to-date knowledge of the subject and is capable of communicating it in a very organised manner; (2) well organised in lectures; (3) approachable and helpful to students; (4) prompt in replying to students' queries; (5) encouraging students to do their best; (6) friendliness with students; (7) having a passion for teaching; (8) patient and understanding; (9) possessing a positive/enthusiastic attitude; (10) cheerful, delightful and smiling; and (11) open to student feedback.

Table 1: Self-reflection as a learner

\begin{tabular}{|c|c|}
\hline Qualities I liked & Qualities I disliked \\
\hline \multicolumn{2}{|l|}{ 1. Characteristics of the lecturer: } \\
\hline $\begin{array}{l}\text { - Helpful lecturers with a friendly nature } \\
\text { - Being punctual } \\
\text { - Respecting students' views } \\
\text { - Listening to students' concerns and issues }\end{array}$ & $\begin{array}{l}\text { - Arrogant lecturers who perceive } \\
\text { themselves superior to everyone else, } \\
\text { particularly to students } \\
\text { - Being late to class or not turning up for } \\
\text { class and wasting students' time } \\
\text { - Partial/discriminatory lecturers }\end{array}$ \\
\hline \multicolumn{2}{|l|}{ 2. Course delivery methods: } \\
\hline $\begin{array}{l}\text { - Using a variety of techniques such as } \\
\text { lectures, site visits, group tasks, } \\
\text { presentations, and practice-based projects } \\
\text { - Providing one-on-one support in tutorial } \\
\text { classes and for assignments, when needed } \\
\text { - Filling the classroom with bi-directional } \\
\text { communications }\end{array}$ & $\begin{array}{l}\text { - Same format all the time - lectures } \\
\text { followed by labs/tutorials } \\
\text { - Insufficient information or support } \\
\text { provided to students for learning } \\
\text { - In-flexible/boring methods of learning } \\
\text { - One-way communication channel }\end{array}$ \\
\hline \multicolumn{2}{|l|}{ 3. Module resources provided: } \\
\hline $\begin{array}{l}\text { - Well-structured and logically organised } \\
\text { lecture slides/notes } \\
\text { - Full of real-world examples or cases to } \\
\text { explain theories well } \\
\text { - Providing additional materials or information } \\
\text { about further resources }\end{array}$ & $\begin{array}{l}\text { - Boring, wordy slides of theories without } \\
\text { connections to practice or real world } \\
\text { - Repeating teaching materials year after } \\
\text { year without much updating on account } \\
\text { of contemporary developments }\end{array}$ \\
\hline \multicolumn{2}{|l|}{ 4. Assessment methods: } \\
\hline $\begin{array}{l}\text { - Assignment tasks are related to the real } \\
\text { world and manageable in terms of } \\
\text { expectations and the duration for completion } \\
\text { - Well specified submission expectations } \\
\text { - Availability of the lecturer to clarify issues in } \\
\text { the course of preparing the submission }\end{array}$ & $\begin{array}{l}\text { - Being purely theoretical and overly } \\
\text { loaded } \\
\text { - Insufficient time for completion } \\
\text { - Unspecified and unclear submission } \\
\text { expectations/requirements } \\
\text { - Distributing the assessment task and } \\
\text { then leaving everything to students }\end{array}$ \\
\hline
\end{tabular}




\section{Student preferred module delivery methods}

The students' opinions on effective module delivery methods include: (1) teaching skills which are relevant to industry practices - teaching practical modules; (2) well-structured, organised modules and clarity and simplicity in lessons; (3) integrating lectures, tutorials and assignment tasks for better understanding of the subject; (4) interesting and challenging module contents; (5) keeping the lessons productive by engaging students; (6) variety of teaching styles used lectures, tutorials, online quizzes, games, simulations, discussion groups, projects, etc.; (7) using case studies and real world examples; (8) providing hands-on tasks to help students understand theories better and offering one-on-one support to students (if needed); and (9) using modern tools to create interactive and flexible learning environments.

\section{Student preferred qualities of learning resources}

The students perceived that learning resources provided to them should have qualities such as: (1) clearly structured module resources (lecture slides/notes) with adequate explanations and examples embedded; (2) uploading module materials to the learning management system before the class to enable students to add their notes during the class; (3) providing adequate tutorial questions for practice; (4) using online video resources to enable flexible learning off campus; (5) providing past exam papers and past assignments for viewing; and (6) better physical resources adequate room size with necessary infrastructure and technical problems are resolved efficiently.

\section{Student preferred assessment methods}

For assessment methods, the students preferred: (1) using continual assessments rather than a final exam; (2) having a number of small multiple choice quizzes throughout the module with other major assignments; (3) appropriate proportioning of marks among various assessment tasks, depending on the level of efforts involved by students; (4) providing adequate information and instructions for assessment tasks; (5) providing adequate time and support to complete assessment tasks; (6) setting moderately difficult assessment tasks because very difficult ones destroy student confidence; and (7) providing feedback and being reasonable in marking.

\section{Examining with lens 3: learning from colleagues' experiences}

In order to compare and contrast the findings of the above reflections, the author elicited information from four experienced colleagues in the discipline who have secured several awards for teaching excellence. One of the respondents was the recipient of both the Vice-Chancellor's Teaching Excellence Award and the Dean's Teaching Excellence Award. The second respondent has received the Dean's Teaching Excellence Award twice and several commendations from the Associate Dean Education. The other two have received commendations from the Associate Dean Education for receiving better teaching evaluations. The same four themes above were used for the conversation, and the points they raised are discussed below under appropriate question tags.

When the colleagues were asked "In your experience/opinion, what are the qualities that effective lecturers possess?", they highlighted seven features: (1) Empathy - understanding the fact that students have different backgrounds, needs, motivations and skills; (2) Listening to students to understand the differences they bring along; (3) Teaching style is able to cover the learning abilities of the whole cohort - having multiple teaching styles and being able to switch between styles in a class. For example, lecturing (providing structured information), demonstrating with relevant examples/cases, using metaphors, using visual media, etc.; (4) Being able to create a positive atmosphere for students for active learning - better physical layout of the classroom for discussions and interactions; using the whiteboard and/or transparent sheets with overhead projectors for explanation so that students will participate in what you are doing by way of taking 
notes; (5) Strong knowledge base in what you are teaching; (6) Preparation and organisation for what you want to cover and the depth and breadth of it, how you want to deliver, and planning the activities according to time available; and (7) Effective communication and articulation skills - presentation, use of right media, body language, and entertainment.

For the question of "In your experience/opinion, what should be the characteristics of module resources provided to students?", colleagues indicated three aspects: (1) Providing effective module details/outlines at the onset of teaching to inform students of - why they do this subject; how this subject fits in the overall degree and professional competencies required; and what you expect from students in terms of attendance, participation, respect, communication, submissions, etc.' (2) Making available a range of materials to support student learning in both digital and hardcopy formats - background/additional readings for particular topics; inspirational examples/cases; past examples of assignments; and a list of references (web links and references) to relevant materials; and (3) In the preparation of learning resources for students: structuring the coverage logically, enabling self-study by students; link the materials with class tasks and assignments; and optimise the content - not too much or too little.

Likewise, when asked "In your experience/ opinion, what are the qualities of effective delivery methods?", they stressed four habits: (1) Make students feel calmed and engaged in learning instead of stressed out and lost - use humour; maintain consistency in wordings used in learning materials and verbal explanations provided; have short burst lectures; interact with students individually; (2) Don't hide behind the lectern, rather, walk around the class and interact with students - this reduces students using distractors such as mobile phones, laptops, etc. during the class; (3) Make a balance between the use of pre-populated power point slides and whiteboards/transparent sheet for writing in the class. Excessive reliance on power point slides dumb the class and students become passive and do other things without participating in learning; and (4) Use cases to anchor teaching onto contexts - provide situated learning.

Finally, for the question of "In your experience/opinion, what are the qualities of effective assessment methods?', colleagues suggested five techniques: (1) Using a mix of assessment tasks to suit the nature of the module and students - in class tasks/quizzes; research assignments; exams; reflective journals, etc.; (2) An assessment task provided to students must be clear in terms of: objectives of doing it; how it fits into the overall module structure; submission expectations; and how it is going to be assessed; (3) Provide rapid detailed feedback and maintain consistency in feedback style with the use of a template; (4) Use group assignments in large classes to promote discussions and collaborative learning; and (5) Encourage peer reviews.

\section{Examining with lens 4: engaging with pedagogical literatures}

In an attempt to view teaching and learning through the lens of pedagogical scholarships, the author undertook a comprehensive review of literatures on university learning and teaching and identified critical variables of quality learning and teaching in higher education; the findings are summarised below.

The framework that was developed in the UK to measure the quality of university teaching highlighted six characteristics of effective university teaching, which are: (1) Teaching - the lecturer is good at explaining things, makes the subject interesting and intellectually stimulating and is passionate about teaching; (2) Assessment and feedback - clear marking criteria notified in advance, fair assessment arrangements, prompt feedback, and feedback is helpful to clarify matters that students faced challenges with; (3) Academic support - adequate learning scaffolding from lecturers and accessibility of lecturers; (4) Organisation and management - the module is well structured and any changes are communicated effectively; (5) Learning resources - adequate resources provided for learning, which are easily accessible; and (6) Personal development - 
nurturing students confidence, improved communication skills and increased problem solving abilities (the National Student Survey 2013).

Kember and McNaught (2007) suggested nine indicators of effectiveness in learning and teaching, including: (1) the module content is enough to explain concepts well; (2) application focused teaching (theory is related to applications); (3) challenging students' thinking; (4) promoting student engagements and active learning; (5) better teacher-student relationships (communication, friendly environment, attention to individuals); (6) motivating students to learn; (7) better organisation of the module; (8) flexibility in learning; and (9) assessment tasks are authentic for the discipline and consistent with the desired learning outcome. They further suggested the use of active learning tactics such as projects, case-based teaching, problem-based learning, reflective journals, and experiential learning to facilitate deep learning.

In a similarly vein, Hativa (2000, p.332) identified three dimensions of effective teaching: (1) Organisation - linking the lesson to the previous one and to the overall framework of the module, and dividing the lesson or the topic into subtopics; (2) Interest/engagement - motivating to study, presenting intellectual challenges, introducing diversity into the lesson, and activating students during the lesson; and (3) Positive classroom climate - demonstrating care for students and their learning, behaving respectfully towards them, providing encouraging feedback, and being accessible.

Liu, et al. (2012) argued it is crucial that modules are designed such that learning tasks inherently motivate students' active engagement, and motivation depicts a strong, positive correlation with high-level cognitions. Kamardeen (2013) proposed a six-element model to assist the development of a motivating module. These elements include: (1) developing module curriculums that are relevant to real world issues; (2) using blended delivery methods that promote active learning; (3) incorporating application-focused assessments and providing prompt and balanced feedback to students; (4) recognising students' efforts and performance via encouraging remarks and/or rewards; (5) maintaining a close yet professional relationship with students; and (6) creating an interactive classroom environment. Chandler and Mayer (2001) postulated that interactive learning environments that enable students to have some control over their learning progress offer better benefits to students. Kamardeen (2014) demonstrated that the utilisation of adaptive eLearning tasks would provide such a learning experience for students.

\section{Formulation of a New Pedagogical Model}

Carefully consolidating the findings unearthed above with the four lenses, a new model for leading a critically reflective teaching practice is synthesised, as shown in Figure 2. The model theorises that students enrolled in a particular subject would realise a quality learning experience and outcomes only when the lecturer adheres to and embraces certain key principles governed by the four core pillars of teaching practice, known as: lecturer's characteristics, module contents, delivery strategies and assessment methods.

The first pillar, lecturer's characteristics, proposes that lecturers should possess six vital traits, viz.: (1) keep abreast of the latest developments in knowledge and industry practices related to the subject, by attending academic conferences and industry forums, seminars and workshops; (2) show a passion for teaching the students by enthusiastically engaging with them with a positive attitude; (3) recognise and be considerate of differences they pose in cognitive and physical capabilities, and other study/personal circumstances, which impact of learning; (4) adopt clear communication and explanation methods in class with the use of short-burst deliveries/discussions, real-world examples and visual media as well as retain students' interest by entertaining learning; (5) support students to do their best and be easily approachable both during and outside class hours to clarify student queries; and (6) demonstrate good organisational 
competencies with punctuality, better structures of in-class activities and prompt updating on issues that affect learning progress.

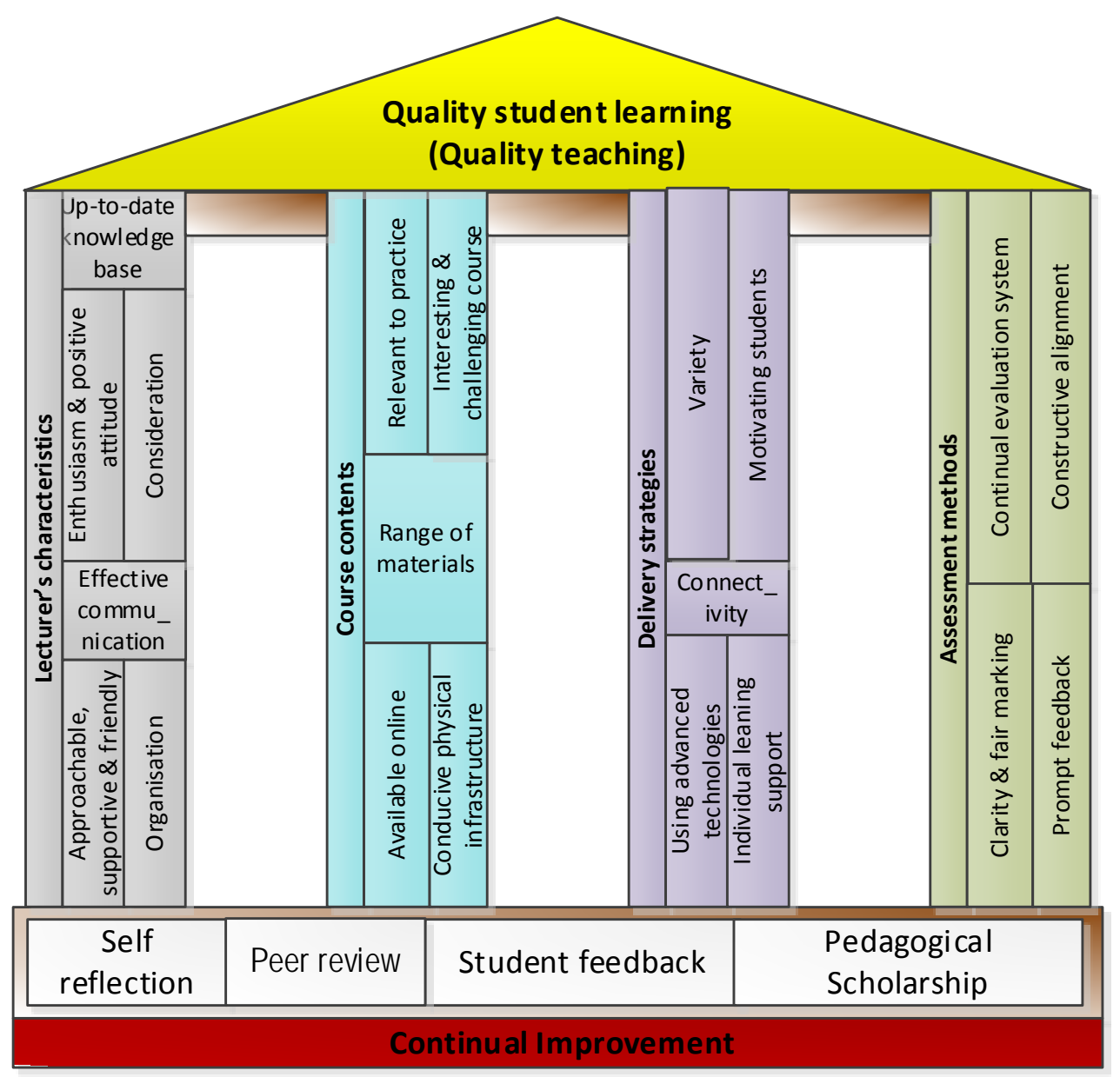

Figure 2: Model for critically reflective teaching practice

The second pillar establishes five quality requirements for module content that lecturers should meet. These are articulated as: (1) make connections between current real-word scenarios and theories discussed, and avoid teaching pure theories without applications; (2) develop challenging, yet manageable, learning tasks that provoke deep learning; (3) provide a range of materials to support learning, such as additional readings, inspirational cases/documentaries, samples of past assignments, video recordings of the lectures, etc.; (4) offer flexible learning opportunities by making tasks and materials available online; and (5) organise classroom layouts and infrastructure compatible with the learning activity taking place on a given day.

The third pillar, delivery strategies, urges lecturers: (1) utilise a blended delivery model by mixmatching lectures, hands-on exercises, online activities such as forums, blogging, etc., games and competitions, projects/case studies, eQuizzes, class presentations, etc.; (2) stimulate students' motivation and confidence by recognising their efforts and achievements openly in the class with encouraging remarks, rewards and/or bonus points; (3) articulate the connections between previously known knowledge and the current lesson, as well as assessment tasks and lessons; (4) leverage advanced eLearning technologies, like adaptive eLearning, social media and other web 2.0 tools, to embrace student-driven deep learning; and (5) offer additional support to underachieving students. 
The final pillar sets standards to be followed by lecturers in designing assessments to stimulate learning. They are: (1) adopt the continual evaluation system with more formative and less summative (e.g. final exam) tasks to provide students with multiple opportunities to demonstrate capabilities; (2) reinforce learning and better understanding of the subject through constructive alignment of assessment tasks with module contents, learning outcomes and real-life scenarios; (3) frame the performance expectations and marking criteria explicitly, and communicate with students from the onset; and (4) provide forward-looking timely feedback to allow students to act on, remediate and subsequently improve.

The practical strategies used by lecturers in meeting the key principles in the four pillars are not static, rather they need to be continually improved in response to: (1) insights and reflections drawn from personal teaching and learning experience; (2) feedback given by students, both formally and informally, on teaching and the subject; (3) lessons learnt from peers through collegial feedback and/or from success and failure stories of colleagues; and (4) advancements in pedagogical scholarship.

\section{Model Testing and Validation: a Case Study}

The model was tested in the Construction Management Degree Program at the University of New South Wales, specifically in one of the modules taught by the author, namely Construction and Property Economics. The selection of this particular module for the case study was deliberate. The module is categorised as large with student enrolments up to 150, which posed enormous challenges for providing deep learning opportunities to students. The utilisation of the model as the case thus served two purposes: (1) the model was tested and validated in one of the difficult contexts, thus proving to be effective, and (2) applying the model in the module would allow refinement of it to overcome the challenges that have been faced thus far. The accounts below explain how the model was applied in the said module and how students rated the quality of teaching and learning they received through the new approach.

\section{Application of the new pedagogical model in instructional design}

The model was implemented in the first year core-module, which teaches topics such as building design economics, construction investment appraisal, cost benefit analysis for public infrastructure projects, and the construction industry and the national economy. The author had taught the same module in previous years with the conventional delivery model, which involved lectures, tutorials, assignments and a final exam. This time though the author significantly revised the teaching practice for the module in view of the proposed pedagogical model. The sections below expound how the four pillars of the proposed pedagogical model were operationalised in the module.

\section{Applied module contents}

Scenario-based learning was centred on module contents development whereby lecture content and tutorial tasks were tightly linked to real-world situations, enabling the applications of theories to practice. For instance, actual house designs from the Australian home building industry and video clips of construction methods were used for explaining design economics in perspectives; local property development projects were utilised for discussing construction investment appraisals; the proposed East Coast High Speed Rail Network in Australia was interwoven in explaining cost benefit analysis for public projects; and the dynamic relationships between the local construction industry and the Australian economy were described by correlating the recent national and state-wide policy changes to the trends in construction demand and supply. 


\section{Blended delivery strategy}

The delivery strategy was a blend of online and offline learning, which comprised regular lectures, tutorials and hands-on exercises, competitions, case-based learning and adaptive e'Tutorials.

The lectures often started with an opening real-world problem and the theory was linked to resolving the problem. Moreover, each lecture was split into multiple short bursts to provoke regular discussions and lecturer-student interactions, thereby maintaining students' interest in the topic. Lecture slides were made available online prior to the lecture to enable students to take extra notes during class discussions. Moreover, video recordings of the lectures were made available on Moodle learning management system.

Tutorials offered hands-on exercises to allow students to apply theories learnt in the class to solve simulated problems. Students were urged to work in small groups of five and discuss and debate their solutions. Moreover, competitions were conducted over the exercises and winning groups/students were awarded prizes to encourage all students.

Adaptive eTutorials were provided in the module to drive self-directed learning off campus at students' own time, location and pace. The adaptive eTutorial tasks were made available on Moodle prior to a class test. Students were required to answer questions and pre-programmed real-time feedback was given to their answers. The feedback was of two kinds: when a student provides a correct answer, a real-time encouraging comment is displayed; and on the other hand, if a student chooses an incorrect answer, feedback with hints is displayed to enable the student to redo the question until he/she gets it right.

\section{Integrated assessment scheme ${ }^{1}$}

Following the principles of constructive alignment, an integrated assessment scheme of formative and summative tasks was formulated for the module by amalgamating case-based assessment tasks, online quizzes and a class test to provide a variety of assessments, aligned with lecture and tutorial topics.

Students were required to complete two case-based assessment tasks in groups of five. The first task dealt with the economics of building designs, where students had to make oral presentations on cost optimisation suggestions for real building designs provided to them by the author. The alignment of the task timing with the lecture that discussed economics of building designs enabled students to learn the theory in real contexts. Moreover, the formative and summative feedback provided immediately after their presentations helped students learn further.

In the second case-based assessment, student groups were required to undertake cost benefit analyses of a real world infrastructure development project of their choice (for instance: roads, bridges, dams, railways, airports, tunnels, etc.). This assessment task was introduced just after the lecture that dealt with cost benefit analysis of public projects. Students were expected to undertake a detailed literature review to identify economic, social and environmental costs and benefits of their chosen project type. For example, if a group chose a road project for analysis, they were first required to undertake a literature review on economic, social and environmental costs and benefits of roads. Then the group would apply the knowledge in analysing the selected case. Extensive analyses, including benefit cost ratio calculations and sensitivity testing, constituted the task. Student groups were required to submit a full report of their study and a period of eight weeks was allocated for the task. Weekly meetings were held with student groups to regularly assess their progress and provide feedback for remediation. Students were enthusiastically involved in the assessment as they were studying projects of interest to them and

\footnotetext{
1 A detailed account of the integrated assessment scheme applied in this module has been published in another article by the author, cited as Kamardeen (2014).
} 
from their locality. For both case-based assessments, detailed marking criteria were made available at the onset, which enabled students to self-assess their work from time to time as they progressed.

Three online quizzes were utilised apart from the case-based tasks. At the start of the lectures, students were informed that they would have to complete an online quiz for the topic covered in the lecture on that day. As such, students became more attentive in the lecture and more diligent in completing exercises in tutorial classes than previous years when no online quizzes were used. The end-of-session class test functioned as a final, summative evaluator of all topics taught in the session.

\section{Positive lecturer characteristics}

The author constantly adopted the following behavioural standards in demonstrating positive lecturer characteristics that inspire students to learn:

- The author was always punctual and well organised and prepared for teaching. He showed enthusiasm and a passion for teaching the students by being active, walking around the class, talking vibrantly and enthusiastically engaging with students with a positive attitude. At times, entertaining students with jokes helped to eliminate boredom. Moreover, students who voluntarily contributed to learning tasks during lectures and tutorial exercises were openly encouraged with positive remarks.

- The author took every effort to make students who had study, disability or personal issues feel that their problems are considered promptly and appropriately. Moreover, email enquiries from students were swiftly responded to.

- The author was friendly and kind, yet professional with every student. Even some disruptive and rude students were calmed down by a soft approach. He put effort into knowing most students by their names and their study individual circumstances. This enabled close interactions throughout the module and students liked being known to the lecturer personally.

\section{Effectiveness of the new pedagogical model}

Quality of learning and teaching was used as the indicator to measure the effectiveness of the above teaching practice, which is essentially the manifestation of the new pedagogical model. The author's institution conducts an online survey at the end of each teaching session to receive students' feedback on the quality of teaching they received from lecturers. The survey requires students to answer seven questions on a 6-point Likert scale. The questions are shown in the first column of Table 2. Accordingly, all 147 students who had enrolled in the module were invited to complete the survey, but only 75 of them responded, making a response rate of $51 \%$. Descriptive statistics of student responses are shown in columns 2 to 4 of Table 2 .

A comparison was also undertaken whereby the mean responses for the questions from this year were compared with the corresponding means in a previous year when this pedagogical model was not applied. As shown in Figure 3, the mean quality ratings for the post-model session are higher than the values for the pre-model session. This suggests that the proposed pedagogical model has been effective in improving learning and teaching. Further comparisons were made to evaluate the standing of the responses for this module in the overall ratings for the author's faculty and the university as a whole. Figure 4 illustrates the comparative analysis results. The results from both analyses validate the suitability of the new model for its intended purpose of enhancing learning and teaching in higher education. 
Table 2: Descriptive statistics of survey responses

\begin{tabular}{|l|c|c|c|}
\hline \multicolumn{1}{|c|}{ Survey question } & $\begin{array}{c}\text { Median } \\
\text { response }\end{array}$ & $\begin{array}{c}\text { Mean } \\
\text { response }\end{array}$ & $\begin{array}{c}\text { Standard } \\
\text { deviation }\end{array}$ \\
\hline $\begin{array}{l}\text { 1. } \\
\begin{array}{l}\text { This lecturer communicated effectively with students (e.g. } \\
\text { He / She explained things clearly). }\end{array}\end{array}$ & 5 & 5.03 & 0.88 \\
\hline $\begin{array}{l}\text { This lecturer stimulated my interest in the subject matter } \\
\text { he/she was teaching. }\end{array}$ & 5 & 4.93 & 1.06 \\
\hline 3. $\quad$ This lecturer encouraged me to think critically. & 5 & 5.11 & 0.88 \\
\hline 4. $\quad$ This lecturer provided feedback to help me learn. & 5 & 5.03 & 0.87 \\
\hline 5. $\begin{array}{l}\text { This lecturer encouraged student input and participation } \\
\text { during classes. }\end{array}$ & 5 & 5.32 & 0.93 \\
\hline 6. $\quad$ This lecturer was generally helpful to students. & 5 & 5.23 & 0.72 \\
\hline 7. $\begin{array}{l}\text { Overall, I was satisfied with the quality of this lecturer's } \\
\text { teaching. }\end{array}$ & & & \\
\hline
\end{tabular}

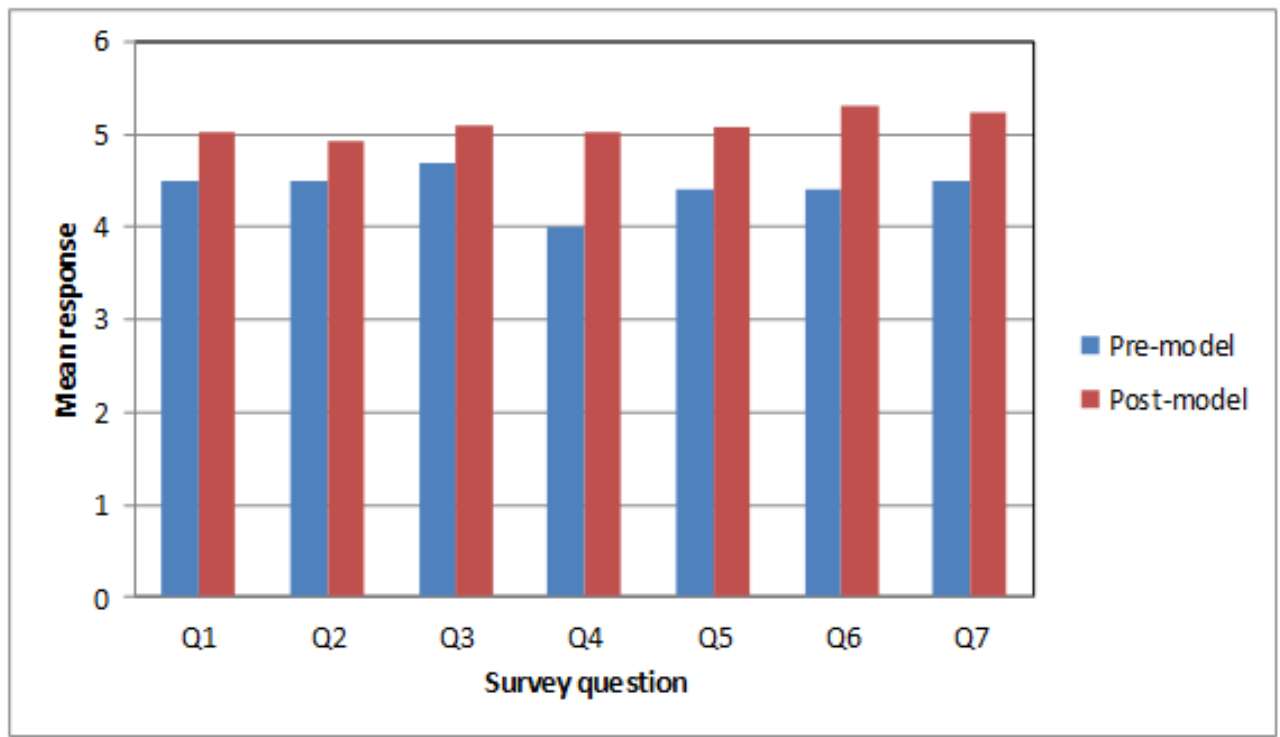

Figure 3: Comparison of pre and post model implementation outcomes

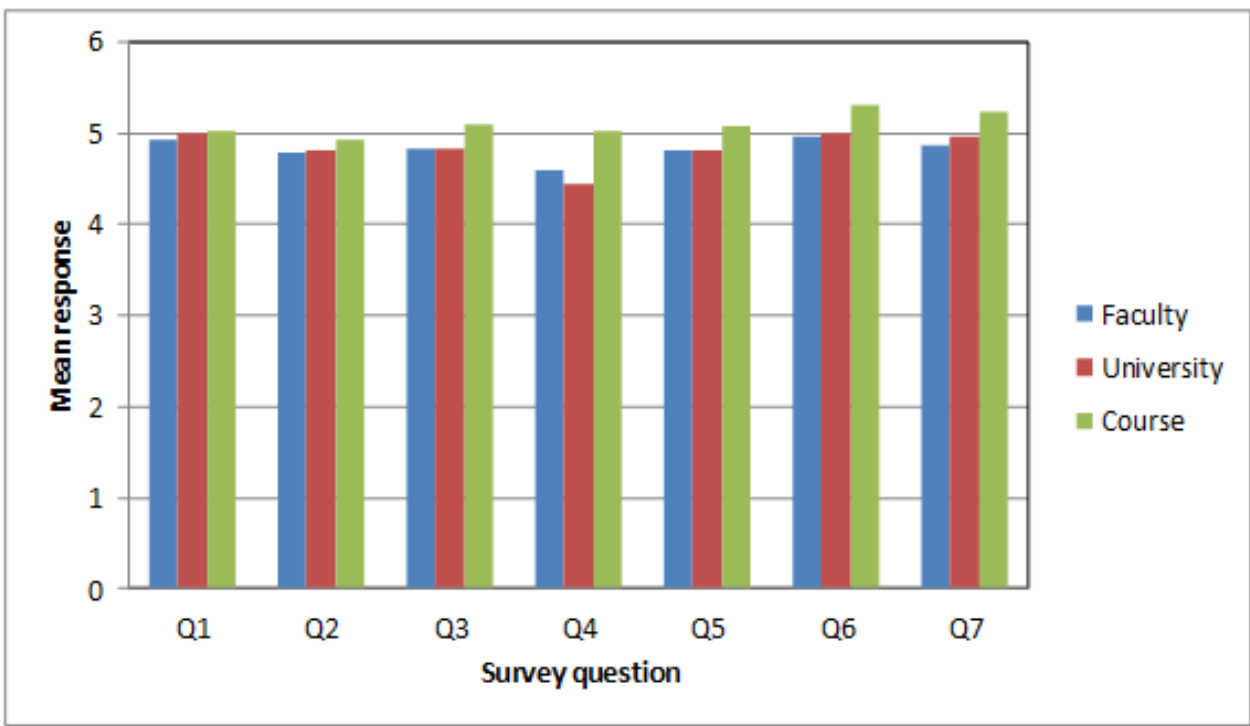

Figure 4: Overall comparison 


\section{Conclusion}

This study demonstrated the pathway by which a construction management lecturer can become a critically reflective educator. The study also proposes a validated pedagogical model for them to lead a critically reflective teaching practice, which would allow students to gain quality learning experiences. The adoption of the model in a lecturer's academic portfolio, as a blueprint to guide instructional design, would produce significant implications for both students and lecturers. These are: (1) it would ensure that university teaching is in tight alignment with contemporary industry needs and practices; (2) students would be industry-ready and confident on graduation owing to their previous exposure to industry practices through university courses; and (3) it would help lecturers to continually improve teaching quality and thereby receive recognition and positive feedback.

Although the model proposed in this study has been developed in the context of construction management education and has been proven to be effective for that same discipline, it may be suitable for other discipline too. Further research can be undertaken to test its applicability in, and benefits for, other disciplines.

\section{References}

Brookfield, S., 1995. Becoming a Critically Reflective Teacher. San-Francisco: Jossey-Bass.

Chandler, P. and Mayer, R.E., 2001. When learning is just a click away: does simple user interaction foster deeper understanding of multimedia messages? Journal of Educational Psychology, 93(2), pp.390-97. doi: http://dx.doi.org/10.1037/0022-0663.93.2.390

Hativa, N., 2000. Teaching for Effective Learning in Higher Education. Dordrecht, The Netherlands: Kluwer Academic Publishers. doi: http://dx.doi.org/10.1007/978-94-010-0902-7

Johns, C., 2002. Guided Reflection: Advancing Practice. Oxford, UK: Blackwell Science.

Kamardeen, I., 2013. Motivation-Driven Learning and Teaching Model for Construction Education. Australasian Journal of Construction Economics and Building, 13(1), pp.36-49. doi: http://dx.doi.org/10.5130/ajceb.v13i1.3124

Kamardeen, I., 2014. Stimulating learning with integrated assessments in construction education. Australasian Journal of Construction Economics and Building, 14(3), pp.86-98. doi: http://dx.doi.org/10.5130/ajceb.v14i3.4152

Kember, D. and McNaught, C., 2007. Enhancing University Teaching. London: Routledge.

Le Cornu R. and Peters J., 2005. Towards constructivist classrooms: the role of the reflective teacher. Journal of Educational Enquiry, 6(1), pp.50-64.

Liu, E.Z., Lin, C., Jian, P and Liou, P., 2012. The dynamics of motivation and learning strategy in a creativitysupporting learning environment in higher education, The Turkish Online Journal of Educational Technology, 11(1), pp.172-80.

McKay S.L., 2007. Reflective Teaching Practices. Available at: http://www.cape.edu/docs/TTalk0032.pdf. [Accessed16 Apr 2014].

Rolfe, G., Freshwater, D. and Jasper, M., 2001. Critical Reflection for Nursing and the Helping Professions: a User's Guide. Basingstoke: Palgrave.

Schon, D., 1990. Educating the Reflective Practitioner. San Francisco: Jossey-Bass.

The National Student Survey, 2013. The National Student Survey Questionnaire. Available at: http://www.thestudentsurvey.com/content/nss2012_questionnaire_english.pdf [Accessed 25 March 2013]. 